\title{
ALCOHOL DRINKING IN PREGNANT WOMEN FROM AN ARGENTINIAN CITY
}

\section{CONSUMO DE ALCOHOL EN MUJERES GESTANTES DE UNA CIUDAD ARGENTINA}

\author{
Aldana Lichtenberger ${ }^{1,2,3}$, Karina Conde ${ }^{1,2,3}$, Raquel Inés Peltzer ${ }^{1,2,3}$, María Ayelén Biscarra ${ }^{1,2,3}$, Santiago Gonzáles ${ }^{4}$ \& Mariana \\ Cremonte ${ }^{1,2,3}$ \\ ${ }^{1}$ Consejo Nacional de Investigaciones Científicas y Técnicas. Argentina \\ ${ }^{2}$ Universidad Nacional de Mar del Plata. Argentina \\ ${ }^{3}$ Instituto de Psicología Básica, Aplicada y Tecnología. Argentina \\ ${ }^{4}$ Secretaría de Salud Mental del Municipio de General Pueyrredón. Argentina
}

\section{Abstract}

Alcohol drinking during pregnancy might lead to detrimental consequences to the mother and fetus, being Fetal Alcohol Syndrome (FAS) the most severe. In many Latin-American countries, there is a paucity of information about prenatal exposure to alcohol. Aim. To estimate alcohol drinking in pregnant women and describe it concerning sociodemographic characteristics. Method. Data were collected from a random sample of women attending the public health care system ( $N=852)$ in 2016. Alcohol drinking, including binge drinking (BD), was evaluated before and after pregnancy recognition. Descriptive and bivariate analyses were performed. Results. While pregnant, two out of ten women reported drinking. Moreover, 2\% engaged in BD and 3\% presented indicators of alcohol dependence. BD before pregnancy was related to drinking during pregnancy and frequency, quantity, and BD before pregnancy with BD during pregnancy. Conclusions. Alcohol consumption in pregnant women was higher than the estimated for most LatinAmerican countries, and of the considered characteristics, was almost exclusively related to consumption patterns before pregnancy.

Keywords: Alcohol, binge drinking, pregnant women, congenital abnormalities, Argentina.

\section{Resumen}

Consumir alcohol durante la gestación tendría consecuencias perjudiciales para madre y feto, siendo el Síndrome Fetal Alcohólico (SFA) la más grave. En países latinoamericanos la información sobre la exposición prenatal al alcohol es escasa. Objetivo. Caracterizar el consumo de alcohol durante la gestación y describirlo en función de variables sociodemográficas en mujeres argentinas. Método. Se utilizó una muestra probabilística de mujeres que asistieron al sistema de salud pública $(N=852)$ en 2016. Se evaluó el consumo de alcohol y consumo excesivo episódico (CEEA) antes y después de reconocer el embarazo. Se realizaron análisis descriptivos y bivariados. Resultados. Dos de cada diez mujeres informaron haber bebido durante el embarazo. El 2\% se involucró en CEEA y el 3\% presentó indicadores de dependencia. El CEEA antes se relacionó con el consumo de alcohol durante el embarazo, y la frecuencia, cantidad y CEEA antes con el CEEA durante el embarazo. Conclusiones. El consumo de alcohol en gestantes fue mayor que el estimado para la mayoría de Latinoamérica, y dentro de las características consideradas, se relacionó casi exclusivamente con el consumo antes del embarazo.

Palabras clave: Alcohol, consumo excesivo episódico de alcohol, mujeres gestantes, anomalías congénitas, Argentina. 
Although the evidence of potential harms from drinking low doses of alcohol during pregnancy is limited (Mamluk et al., 2017), alcohol could have negative effects on pre and postnatal fetal development, and no dose is considered safe. Consuming alcohol at any stage of pregnancy (Ikonomidou et al., 2000; Sood et al., 2001) increases the chances of suffering fetal death (Kesmodel, Wisborg, Olsen, Henriksen, \& Secher, 2002), spontaneous abortion (Henriksen et al., 2004), low birth weight, premature delivery, low gestational age (Patra et al., 2011) and a whole spectrum of physical, mental, behavioral and/or learning disabilities of the fetus, known under the term Fetal Alcohol Spectrum Disorders (FASD) (Dörrie, Föcker, Freunscht, \& Hebebrand, 2014; Ramsay, 2010). Consequences of prenatal alcohol exposure last for a lifetime and are 100\% preventable if no alcohol is consumed during pregnancy (Centers for Disease Control and Prevention (CDC), 2002; Riley, Infante, \& Warren, 2011), so timely prevention becomes essential.

Alcohol drinking is customary in Argentina, and some women believe that consuming low doses during pregnancy would be acceptable (López, 2013). Furthermore, in many countries, alcohol consumption during pregnancy is rarely detected in regular prenatal care (Göransson, Magnusson, \& Heilig, 2006). In Argentina, only $17 \%$ of pregnant women reported having received a specific recommendation about alcohol consumption by the attending health professional (López, 2013).

Besides, many countries have reported a rise in alcohol consumption among women (White et al., 2015) which translates into an increased risk of drinking during pregnancy (Skagerstrom, Chang, \& Nilsen, 2011). The way women drink before the conception may play a role in drinking during pregnancy, as well as in unintended pregnancies (Naimi, Lipscomb, Brewer \& Gilbert, 2003). Argentina has one of the highest per capita alcohol consumptions in the region among women (World Health Organization, 2014) and 75\% have reported alcohol consumption at least once during pregnancy, and $15 \%$ having engaged in binge drinking (BD) (López, Arán Filippetti, \& Cremonte, 2015). Furthermore, BD during pregnancy is associated with more severe consequences of FASD, like Fetal Alcohol Syndrome (FAS) (Sayal et al., 2009). Addressing the scarceness of data from Latin American countries, and the widely differing prevalence reports for Argentina (López et al., 2015; Popova, Lange,
Probst, Gmel, \& Rehm, 2017) this study aims to estimate alcohol drinking in pregnant women and describe it concerning sociodemographic characteristics.

\section{METHOD}

\section{Participants}

A systematic sample of 897 pregnant women attending Public Health Care Centers in the city of Mar del Plata, Argentina was collected between Apryl and September of 2016. Twelve women refused and three left the questionnaire incomplete, leaving a sample of 882 pregnant women, who were personally interviewed. Eligibility criteria included: a) being pregnant, b) giving informed consent after reading the information sheet, c) having a permanent address in the city and d) being able to understand the questions. The sample size was estimated based on Van del Wulp et al., 2014, as part of a larger project to reduce alcohol consumption among pregnant women.

Mar del Plata is a middle size city in the most populated state in Argentina, Buenos Aires. Half of the city population is female $(52 \%)$, and $40 \%$ of the women are on reproductive age (between 15 al 44 years old) (Instituto Nacional de Estadística y Censos, República Argentina (INDEC), 2010). Women were approached when waiting for either a prenatal appointment or a routine fetal ultrasound scan.

\section{Instruments}

For this descriptive study, measures of alcohol consumption were assessed 12 months before pregnancy recognition (BPR) and after pregnancy recognition (APR). The structured questionnaire contained:

Alcohol consumption. Habitual alcohol consumption was evaluated through the quantity and frequency of drinking. The quantity was estimated in drinks ( 1 drink= $11 \mathrm{~g}$ of alcohol) (Cremonte, Cherpitel, Borges, Peltzer, \& Santángelo, 2010). Frequency of consumption was categorized in monthly or less, 2-4 times a month, 2 or 3 times a week, and 4 or more times a week. Lifetime abstainers were those women who had never drank alcohol; past-year abstainers were those who did not drink in the past 12 months but had drunk before; while 
pregnancy abstainers were those who refrained from drinking since found out about their pregnancy but had drunk alcohol before.

Risky alcohol consumption and dependence indicators. Risky alcohol consumption was estimated through the Alcohol Use Disorders Identification Test (AUDIT) (Babor, de la Fuente, \& Saunders, 1992). The AUDIT is a 10-item questionnaire developed by the World Health Organization to detect at-risk, harmful, or heavy drinking. The AUDIT has shown adequate psychometric properties in Argentine pregnant women ( $\alpha=.93$, Se $=87 \%, \mathrm{Sp}=86 \%$ ) (López, Lichtenberger, Conde, \& Cremonte, 2017). Risky consumption was considered when the BPR score was equal to or greater than eight, and when the APR score was equal to or greater than one (López et al., 2017). Possible dependence was considered when the BPR scores were equal to or greater than 16 (Babor et al., 1992), and when the APR scores were equal to or greater than four (López et al., 2017).

Binge drinking. BD was estimated with an item inquiring about the frequency of consumption of four or more drinks per occasion at least once in the last 12 months for BPR. APR, it was considered positive when the woman referred consumption of four or more drinks of alcohol per occasion at least once since pregnancy recognition.

Sociodemographic characteristics. Age (in years), number of children, marital status, religion, education level, occupation, and socioeconomic status were recorded. The socioeconomic status was determined by the Graffar scale (Castellano \& de Méndez, 1994). The Graffar scale considers four dimensions: the occupation of the person with the highest income in the household, parental education level, the main source of income, and housing conditions.

\section{Procedure}

Data were collected from April to September 2016. Pregnant women attending public centers for prenatal check-ups (obstetric consultation or ultrasound) were approached and interviewed while in the waiting area. At the beginning of the interview, the scope of the research and ethical aspects such as anonymity, voluntary participation and use of the collected data were informed to the participant. Written informed consent was obtained in every case. The whole procedure took approximately 20 minutes and was conducted by trained researchers. Those cases in which alcohol dependence was suspected were advised to seek specialized care and referred to the Mental Health area of the care centers.

The study was evaluated and approved by the Bioethics Committee of the General Hospital "Dr. Oscar Allende" and endorsed by the City's Health Secretary, Argentina.

\section{Data analysis}

Descriptive analysis of the prevalence of alcohol consumption (quantity and frequency), BD, risky alcohol consumption and possible dependence BPR/APR, and sociodemographic variables were made. Differences in alcohol consumption BPR/APR were estimated with the Mann Whitney $U$ test. The association between drinking variables BPR (predictors=frequency and quantity of drinking and BD) and drinking APR (outcome) was estimated through single (unadjusted) logistic regressions. We also explored the association between drinking variables BPR (independently for quantity and frequency of drinking and $\mathrm{BD}$ ) and $B D-A P R$ (dichotomous variable yes $=1 /$ no $=0$ ). Single logistic regressions were also carried out to assess the association among sociodemographic variables (predictors) and drinking APR (outcome, dichotomous variable yes $=1 /$ no $=0$ ). The following variables were assessed separately: age, number of children, marital status (married and living with a partner $=1 /$ divorced, widowed and single $=2$ ), religion (yes $=1 /$ no $=2$ ), education level (incomplete elementary $=1$ to complete university $=8$, see Table 1 ), occupation (employee $=1$ to student $=6$, see Table 1 ), and socioeconomic status (Class I $=1$ to Class $V=5$, see Table 1). We also explored the association between sociodemographic variables (same as above, each one as a single predictor) and $B D-B P R$ (dichotomous variable yes = $1 /$ no $=0$ ). Missing data were lower than $1 \%$ in the sociodemographic variables and were deleted from the analyses when present. There were no missing data for alcohol consumption and alcohol-related consequences variables.

All data management, processing, and analysis were performed with the Statistical Package for the Social Sciences (SPSS) for Windows. 


\section{RESULTADOS}

Table 1 shows the participants' descriptive data. Participants were between 14 and 46 years old, with a mean age of $24.86(S D=6.14)$. At the time of the interview, the mean number of weeks of gestation was 19.26 (SD = 8.74). Most women were expecting their first child (37\% (Cl 95\% [34-40]) or had only one (32\% (Cl 95\% [29-35]). More than half $(67 \%, \mathrm{Cl} 95 \%$ [63-70]) were living with a partner. Most participants dropped out of high school and were homemakers. The majority also lived in unacceptable housing conditions (i.e. lack of access to clean water, overcrowding, or not having indoor water closets) (not shown in tables).

Table 1. Socio-demographic description of pregnant women

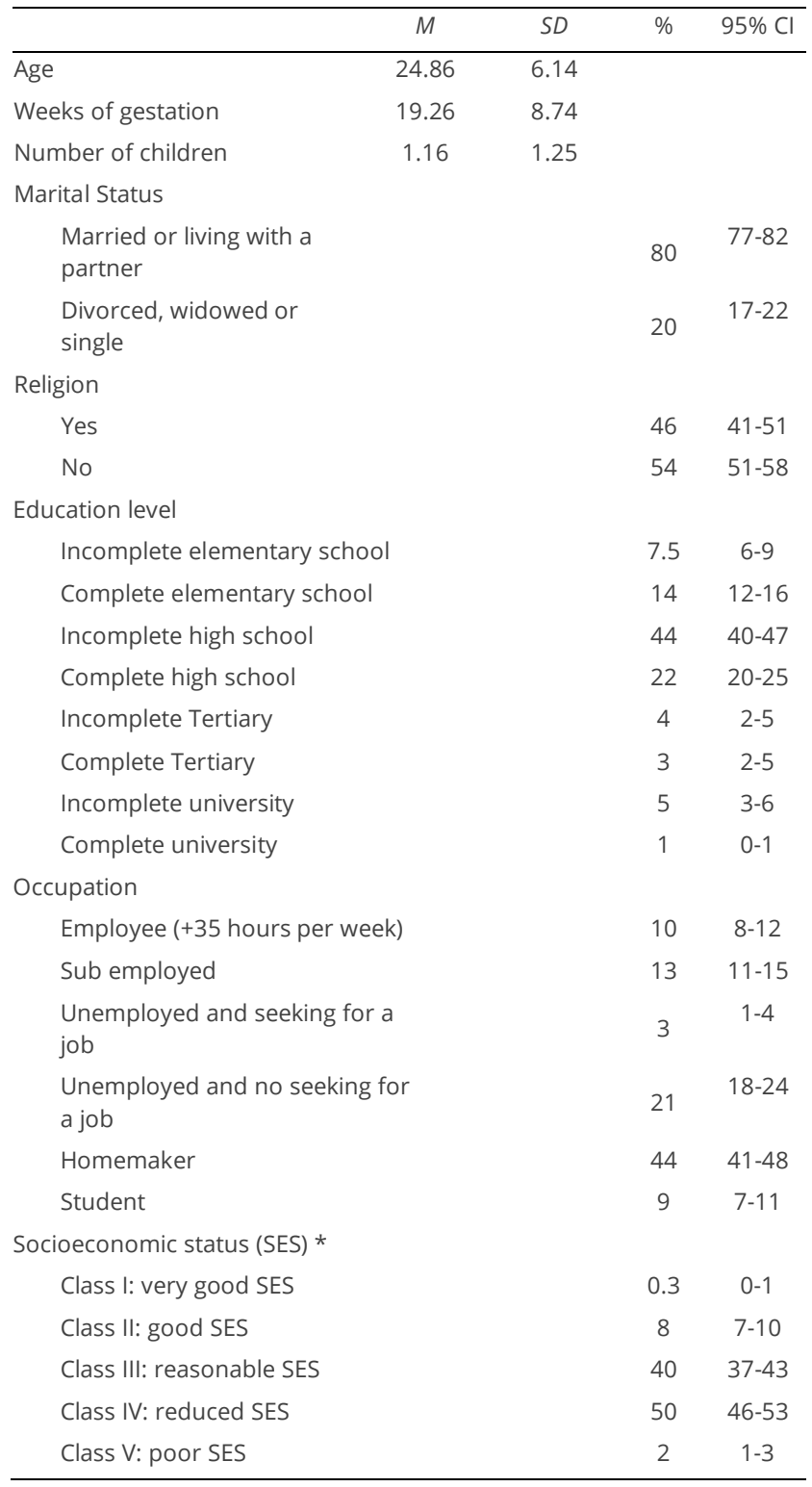

Note: *According to the GRAFFAR scale (Mendez-Castellano \& Mendez, 1994); $\mathrm{Cl}=$ Confidence interval, $N=882$.
From those with a religious belief (46\%), nearly half were Catholic (49\%, Cl 95\% [44-54]) and nearly half Evangelical Christians (48\% Cl 95\% [42-52]) (not shown in tables).

\section{Alcohol drinking BPR and APR}

Three-quarters of participants were drinkers BPR ( $n=661$ ). Among abstainers, $41 \%$ were lifetime abstainers. One percent ( $\mathrm{Cl}$ 95\% [.1-1]) reported being in treatment for substance use at the time of the interview.

From those who were drinkers BPR, 12\% (Cl 95\% [914]) presented risky consumption and 3\% (Cl 95\% [2-5]) possible dependence. Nearly three-quarters of drinkers (74\% Cl 95\% [70-77]) stopped consuming APR (not shown in tables). Among those who continued drinking APR 14\% (Cl 95\% [9-20]) presented indicators of alcohol dependence.

Almost half of the women, who were drinkers BPR, drank alcohol infrequently (once a month or less); this tendency continued APR (Table 2). Among drinkers BPR, more than half of the women tended to drink one or two drinks per occasion (63\% (Cl 95\% [61-68])). Likewise, 88\% (Cl 95\% [83-92])) of women drank that amount per occasion APR. BPR 42\% (Cl 95\% [38-45]) of the women engaged in BD; and 11\% (Cl 95\% [7-16]) APR. The mean number of drinks decreased, by more than a unit, among this group of drinkers (Table 2). This difference was statistically significant $(U=154687, z=-23 ; p<.001)$.

\section{Characterization of drinking APR and BD-APR (outcomes) by drinking BPR and sociodemographic variables}

Higher frequency and quantity of drinking BPR increased the odds of drinking during the pregnancy (OR $=2.60,95 \% \mathrm{Cl}[2.12-3.19] ; \mathrm{OR}=1.68,95 \% \mathrm{Cl}[1.44-1.97])$ and explained the $17 \%$ and $7 \%$ of the variance, respectively. BD-BPR was also related to drinking APR (OR $=3.14,95 \% \mathrm{Cl}[2.23-4.41])$ accounting for $8 \%$ of the variance (Nagelkerke $\mathrm{R}^{2}=.08$ ).

Likewise, a higher frequency of drinking BPR increased the odds of BD-APR (OR $=2.26,95 \% \mathrm{Cl}[1.49$ 3.43]) and explained $16 \%$ of the variance (Nagelkerke $R^{2}=$ .16). A higher quantity of drinking BPR increased the odds of BD-APR (OR $=1.99,95 \% \mathrm{Cl}[1.40-2.83])$ explaining the $34 \%$ of the variance (Nagelkerke $\mathrm{R}^{2}=.34$ ). BD-BPR was also 
strongly associated with BD-APR (OR $=41.59,95 \% \mathrm{Cl}$ [5.52-313.15]) and explained $21 \%$ of the variance
(Nagelkerke $\mathrm{R}^{2}=.21$ ). Sociodemographic characteristics were not associated with drinking APR or BD-APR.

Table 2. Usual quantity and frequency of alcohol consumption and BD, before and after pregnancy recognition

\begin{tabular}{|c|c|c|c|c|c|c|c|c|}
\hline \multirow[t]{2}{*}{ Variable } & \multicolumn{4}{|c|}{ Before pregnancy recognition } & \multicolumn{4}{|c|}{ After pregnancy recognition } \\
\hline & $M$ & $\%$ & $95 \% \mathrm{Cl}$ & $n$ & $M$ & $\%$ & $95 \% \mathrm{Cl}$ & $n$ \\
\hline Lifetime abstainers & & 10 & $8-12$ & 90 & & & & \\
\hline Past-year abstainers & & 15 & $12-17$ & 130 & & & & \\
\hline Total current drinkers & & 75 & $72-78$ & 662 & & 20 & $17-22$ & 176 \\
\hline Quantity (\# drinks) & 2.03 & & $1.87-2.20$ & 882 & .31 & & $.26-.37$ & 882 \\
\hline Quantity (\# drinks) W.A. & 2.71 & & $2.50-2.90$ & 662 & 1.59 & & $1.42-1.80$ & 176 \\
\hline \multicolumn{9}{|l|}{ Frequency W.A. } \\
\hline 2-4 times a month & & 43 & $40-47$ & 287 & & 20 & $14-26$ & 35 \\
\hline 2 or 3 times a week & & 2 & $1-3$ & 12 & & 1 & $1-2$ & 1 \\
\hline 4 or more times a week & & 4 & $3-6$ & 27 & & 3 & $1-6$ & 5 \\
\hline Risky consumption & & 9 & $7-11$ & 79 & & 17 & $15-19$ & 151 \\
\hline Risky consumption W.A. & & 12 & $9-14$ & 79 & & 86 & $80-91$ & 151 \\
\hline Possible dependence & & 2 & $1-3$ & 21 & & 3 & $2-4$ & 25 \\
\hline Possible dependence W.A. & & 3 & $2-5$ & 21 & & 14 & $9-20$ & 25 \\
\hline BD W.A. & & 42 & $38-46$ & 279 & & 11 & $6-16$ & 19 \\
\hline \multicolumn{9}{|l|}{ Frequency BD W.A. } \\
\hline Never & & 58 & $54-62$ & 384 & & 89 & $84-94$ & 157 \\
\hline Less than monthly & & 22 & $19-25$ & 146 & & 6 & $3-10$ & 11 \\
\hline Monthly & & 11 & $9-13$ & 73 & & 1 & $0-3$ & 2 \\
\hline Weekly & & 8 & $6-9$ & 50 & & 3 & $1-6$ & 5 \\
\hline Daily or almost daily & & 1 & $1-2$ & 9 & & 1 & $1-2$ & 1 \\
\hline
\end{tabular}

Note: $\mathrm{Cl}=$ Confidence interval; \# in standard units=11gr of pure alcohol; W.A=Without abstainers; BD=Binge Drinking; $N=882$.

Characterization of BD-BPR (outcome) by sociodemographic variables

Since BD-BPR was strongly related to drinking APR, we assessed sociodemographic characteristics associated with this behavior. Older age and a higher number of children reduced the probability of BD-BPR.
Older age was a weakly related $(\mathrm{OR}=.96,95 \% \mathrm{Cl}[.93-$ $.98]$ ) and constituted $2 \%$ of the variance (Nagelkerke $\mathrm{R}^{2}=$ .02), while a higher number of children slightly reduced the odds of presenting BD-BPR (OR $=.75,95 \% \mathrm{Cl}[.66-$ .85]) and explained $3 \%$ of the variance (Nagelkerke $\mathrm{R}^{2}=$ .03). Marital status and having a religion were also related to BD-BPR. Specifically, being single/divorced/widower 
increased the odds of BD-BPR (OR $=1.86,95 \% \mathrm{Cl}[1.33-$ 2.61]) and explained $2 \%$ of the variance (Nagelkerke $\mathrm{R}^{2}=$ .02); similarly not having a religion increased the odds of BD-BPR (OR $=1.79,95 \% \mathrm{Cl}[1.33-2.40])$, explaining $2 \%$ of the variance (Nagelkerke $\mathrm{R}^{2}=.02$ ). The remaining sociodemographic variables were not associated with BDBPR (Table 3).

Table 3. Single logistic regressions for sociodemographic characteristics and BD-BPR (outcome), pregnant women

\begin{tabular}{lcccc}
\hline Variable & $p$ & OR & Cl 95\% & $\mathrm{R}^{2}$ \\
\hline Age & & & & \\
Number of children & .001 & .96 & $.93-.98$ & .02 \\
Marital Status & .001 & .75 & $.66-.85$ & .03 \\
Religion & .001 & 1.86 & $1.33-2.61$ & .02 \\
Education level & & & & \\
Occupation & .001 & 1.79 & $1.33-2.40$ & .02 \\
Socioeconomic status & .777 & 1.01 & $.92-1.12$ & .00 \\
& .299 & .96 & $.89-1.03$ & .00 \\
\end{tabular}

Note: BD-BPR=Binge drinking before pregnancy recognition (i.e. four drinks per occasion); $\mathrm{Cl}=$ Confidence interval; Outcome= BD-BPR.

\section{DISCUSSION}

This study characterized alcohol drinking among pregnant women attending the public health service of an Argentinean city. The prevalence of women drinkers BPR was higher than the estimated among women of the general population in Argentina (World Health Organization, 2014). This may be due to the age of our participants, mostly young (Observatorio Argentino de Drogas, 2017). Nonetheless, the percentage of life abstainers was slightly higher than the reported for this age group, which could be related to the high number of Evangelical Christians (Protestants) in the sample, who proclaim alcohol abstention.

Two out of ten women reported drinking while pregnant. This percentage not only doubled the estimated for Argentina on a recent study but was also higher than the estimated for most of the rest of Latin American countries (Popova et al., 2017). Nevertheless, is much smaller than the percentage found in previous studies with puerperal women in Argentina (López et al.,
2015). This difference could be partially explained by the time of data collection: while our results were found in the early stages of pregnancy, when women may feel nausea and vomiting and therefore avoid alcohol drinking, the former study accounted for the whole pregnancy.

It is also of interest that we detected women with indicators of risky consumption or dependence, who should ideally receive treatment to reduce their consumption and achieve abstention during the gestational stage. Also, there was a large proportion of women consuming in high quantities. More than a third of the total sample presented BD-BPR, much frequently than once a month, and $11 \%$ continued doing so while pregnant. The lifelong consequences of prenatal alcohol exposure such as the Fetal Alcohol Spectrum Disorders (FASD) and its most severe manifestation, the Fetal Alcohol Syndrome (FAS) are strongly associated with BDBPR and BD-APR (Sayal et al., 2009). Moreover, it has been estimated that one in every 67 women who consumed alcohol during pregnancy would deliver a child with FAS, and several more would deliver a child with other alcoholrelated birth defects (Popova et al., 2017). Notwithstanding, in Argentina, there are no studies regarding the prevalence of FASD or FAS, nor about their burden of disease on public health. In high-income countries, the prevalence of alcohol consumption during pregnancy is significantly lower than in Latin American countries, and while FASD is underdiagnosed, their burden of disease has been estimated at 6.5 million dollars per year (Popova, Stade, Lange, Bekmuradov, \& Rehm, 2011).

Although based on the literature we expected sociodemographic characteristics to be associated with drinking APR, including BD-APR (Bhuvaneswar, Chang, Epstein, \& Stern, 2007), in our study, the only characteristic related to those was pre-gestational consumption, especially BD-BPR. Being single and not having a religion, characteristics associated with youth (Cox, 2015), increased the chances of engaging in BD-BPR, but variance explained by these sociodemographic variables was low. This may be due to the homogeneity of the population regarding these sociodemographic characteristics. Additionally, some other characteristics such as social norms may also explain alcohol drinking in pregnancy. The results, together with the fact that most of the women interviewed had still 21 weeks of fetal 
development remaining and that in a previous study in Argentina the great majority of women drank alcohol during their last month of gestation (López et al., 2015), allows us to assume that there may still be a risk of prenatal alcohol exposure, although at the time of the interview this had not yet occurred.

Our results have some limitations, among them, those resulting from the use of self-reported measures, and the use of a cross-sectional design. Although the sample is presumed to be representative of the pregnant women attending the public health care system, it may not be representative of the private sector, and of other contexts. However, this study presents substantial evidence on alcohol consumption among pregnant women from Argentina, where data about prenatal alcohol exposure were scarce. Furthermore, most of the pregnant women in Argentina do not receive a clear abstinence message (López, 2013), what underlines the urgent need to develop specific prevention plans and clinical guidelines that advice woman to abstain from alcohol during pregnancy, considering regional characteristics. Since BD-BPR was strongly related to drinking APR and of BD-APR, more intensive efforts should target young women, not only those pregnant but those in reproductive age. Finally, analyses with instruments other than AUDIT, and the intake of other psychoactive substances in this population should be addressed in the region.

\section{Acknowledgments}

We are grateful for the collaboration of the members of the Research Group on Psychoactive Substances and Injuries from the Faculty of Psychology, National University of Mar del Plata, Argentina, the staff of the Primary Health Care Centers of the Municipality of General Pueyrredón and all women who gave their consent to participate.

\section{Funding}

This study was funded by the National Council of Scientific and Technical Research (CONICET) through a doctoral scholarship to Aldana Lichtenberger.

\section{REFERENCES}

Babor, T., de la Fuente, J., \& Saunders, J. (1992). AUDIT. The Alcohol Use Disorder Identification Test. Guidelines for Primary Care. Geneva: World Health Organization. Retrieved from: https://apps.who.int/iris/bitstream/handle/10665/67205/WHO MS D MSB 01.6a.pdf;jsessionid=E14A745D0D2DD548B5222345CC1EA 9B6?sequence $=1$

Bhuvaneswar, C. G., Chang, G., Epstein, L. A., \& Stern, T. A. (2007). Alcohol use during pregnancy: Prevalence and impact. Primary Care Companion to the Journal of Clinical Psychiatry, 9(6), 455-460. doi: 10.4088/PCC.v09n0608

Castellano, H. M., \& de Méndez, M. C. (1994). Sociedad y estratificación: Método Graffar-Méndez Castellano. Fundacredesa.

Centers for Disease Control and Prevention (CDC). (2002). Alcohol use among women of childbearing age--United States, 1991-1999. MMWR. Morbidity and Mortality Weekly Report, 51(13), 273-276.

Cox, H. G. (2015). Later life: The realities of aging. Routledge.

Cremonte, M., Cherpitel, C. J., Borges, G., Peltzer, R. I., \& Santángelo, P. R. (2010). Drinking patterns and DSM-IV alcohol use disorders' criteria in Argentinean emergency department patients. Journal of Drug Addiction, Education, and Eradication, 6(3), 209.

Dörrie, N., Föcker, M., Freunscht, I., \& Hebebrand, J. (2014). Fetal alcohol spectrum disorders. European Child \& Adolescent Psychiatry, 23(10), 863-875.

Göransson, M., Magnusson, Å, \& Heilig, M. (2006). Identifying hazardous alcohol consumption during pregnancy: Implementing a researchbased model in real life. Acta Obstetricia Et Gynecologica Scandinavica, 85(6), 657-662. doi:10.1080/00016340600589677

Henriksen, T. B., Hjollund, N. H., Jensen, T. K., Bonde, J. P., Andersson, A., Kolstad, H., ... Olsen, J. (2004). Alcohol consumption at the time of conception and spontaneous abortion. American Journal of Epidemiology, 160(7), 661-667. doi:10.1093/aje/kwh259

Ikonomidou, C., Bittigau, P., Ishimaru, M. J., Wozniak, D. F., Koch, C., Genz, K., . . . Olney, J. W. (2000). Ethanol-induced apoptotic neurodegeneration and Fetal Alcohol Syndrome. Science, 287(5455).

Instituto Nacional de Estadística y Censos, República Argentina (INDEC). (2010). Censo nacional de población, hogares y vivienda. Retrieved from:

https://www.indec.gov.ar/nivel4_default.asp?id tema_1=2\&id tem a 2=41\&id tema $3=135$

Kesmodel, U., Wisborg, K., Olsen, S. F., Henriksen, T. B., \& Secher, N. J. (2002). Moderate alcohol intake during pregnancy and the risk of stillbirth and death in the first year of life. American Journal of Epidemiology, 155(4), 305-312. doi:10.1093/aje/155.4.305

López, M. B., Arán Filippetti, V., \& Cremonte, M. (2015). Consumo de alcohol antes y durante la gestación en Argentina: Prevalencia y factores de riesgo. Revista Panamericana de Salud Pública, 37, 211 217. 
López, M. B. (2013). Saber, valorar y actuar: Relaciones entre información, actitudes y consumo de alcohol durante la gestación. Health and Addictions, 13(1), 35-46.

López, M. B., Lichtenberger, A., Conde, K., \& Cremonte, M. (2017). Psychometric properties of brief screening tests for alcohol use disorders during pregnancy in Argentina. Revista Brasileira De Ginecologia E Obstetrícia, 39(7), 322-329. doi:10.1055/s-0037$\underline{1603744}$

Mamluk, L., Edwards, H. B., Savovic, J., Leach, V., Jones, T., Moore, T. H. M., ... Zuccolo, L. (2017). Low alcohol consumption and pregnancy and childhood outcomes: Time to change guidelines indicating apparently 'safe' levels of alcohol during pregnancy? A systematic review and meta-analyses. BMJ Open, 7(7), e015410-2016-015410. doi:10.1136/bmjopen-2016-015410

Naimi, T. S., Lipscomb, L. E., Brewer, R. D., \& Gilbert, B. C. (2003). Binge drinking in the preconception period and the risk of unintended pregnancy: implications for women and their children. Pediatrics, 111(Supplement 1), 1136-1141.

Observatorio Argentino de Drogas. (2017). Estudio nacional en población de 12 a 65 años, sobre consumo de sustancias psicoactivas. Informe de los principales resultados sobre la población femenina. Buenos Aires: Secretaría de Programación para la Prevención de la Drogadicción y la Lucha contra el Narcotráfico. Retrieved from: http://www.observatorio.gov.ar/media/k2/attachments/INFORMEZ GNEROZHOGARESZWEBZ1-3-19.pdf

Patra, J., Bakker, R., Irving, H., Jaddoe, V. W., Malini, S., \& Rehm, J. (2011). Dose-response relationship between alcohol consumption before and during pregnancy and the risks of low birthweight, preterm birth and small for gestational age (SGA)-a systematic review and meta-analyses. BJOG: An International Journal of Obstetrics \& Gynaecology, 118(12), 1411-1421. doi:10.1111/j.1471$\underline{0528.2011 .03050 . x}$

Popova, S., Lange, S., Probst, C., Gmel, G., \& Rehm, J. (2017). Estimation of national, regional, and global prevalence of alcohol use during pregnancy and fetal alcohol syndrome: A systematic review and meta-analysis. The Lancet Global Health, 5(3), e290-e299. doi:10.1016/S2214-109X(17)30021-9

Popova, S., Stade, B., Lange, S., Bekmuradov, D., \& Rehm, J. (2011). What do we know about the economic impact of fetal alcohol syndrome and fetal alcohol spectrum disorders: a systematic literature review. Alcohol Alcohol 46:490-7. doi:10.1093/alcalc/agr029

Ramsay, M. (2010). Genetic and epigenetic insights into fetal alcohol spectrum disorders. Genome Medicine, 2(4), 27.

Riley, E. P., Infante, M. A., \& Warren, K. R. (2011). Fetal alcohol spectrum disorders: An overview. Neuropsychology Review, 21(2), 73. doi:10.1007/s11065-011-9166-x

Sayal, K., Heron, J., Golding, J., Alati, R., Smith, G. D., Gray, R., \& Emond, A. (2009). Binge pattern of alcohol consumption during pregnancy and childhood mental health outcomes: Longitudinal population-based study. Pediatrics, 123(2), e289-296.
Skagerstrom, J., Chang, G., \& Nilsen, P. (2011). Predictors of drinking during pregnancy: A systematic review. Journal of Women's Health, 20(6), 901-913. doi:10.1089/jwh.2010.2216

Sood, B., Delaney-Black, V., Covington, C., Nordstrom-Klee, B., Ager, J., Templin, T., . . . Sokol, R. J. (2001). Prenatal alcohol exposure and childhood behavior at age 6 to 7 years: I. dose-response effect. Pediatrics, 108(2), E34.doi:10.1542/peds.108.2.e34

Van der Wulp, N. Y., Hoving, C., Eijmael, K., Candel, M. J., van Dalen, W., \& De Vries, H. (2014). Reducing alcohol use during pregnancy via health counseling by midwives and internet-based computertailored feedback: a cluster randomized trial. Journal of medical Internet research, 16(12), e274.

White, A., Castle, I. P., Chen, C. M., Shirley, M., Roach, D., \& Hingson, R. (2015). Converging patterns of alcohol use and related outcomes among females and males in the United States, 2002 to 2012. Alcoholism: Clinical and Experimental Research, 39(9), 1712-1726. doi:10.1111/acer.12815

World Health Organization. (2014). Global status report on alcohol and health-2014. World Health Organization. Retrieved from: https://apps.who.int/iris/bitstream/handle/10665/112736/9789240 692763 eng.pdf?sequence $=1$ 